\title{
Governance of Somali Tertiary Education Systems: A Case Study in Complexity
}

\author{
Abdiqani Ahmed Farah \\ Puntland State University, Commission for Higher Education, Puntland, Somalia
}

\begin{abstract}
Governance of Tertiary Education Systems (TES) in Somalia and how the system of coordination described by Clark (1983) which tries to introduce order of the three dominating forces of educational system: "the state, the market and oligarchy", is examined in this paper. How comparatively Higher Education Systems (HES) is structured, or inadvertently coordinated, arranged and rearranged since the formal Higher Education (HE) has been introduced into Somali nation state will also be examined from a vantage point of whether this trend is in line with other nations' conventional TES. In the first twenty years, the dynamic system of coordination, which according to Clark introduces order into the three dominating forces of the Somali educational system, could not have been possible, as only the state owned and bank-rolled all Higher Education Institutions (HEI) that existed at the time. Thus the "academic oligarchy and the market" took a secondary role. The incentive of job guarantees for the new graduates by the authority made difficult to estimate the 'quality of the education', which in turn, could have compromised their ability and efficiency in their professional contexts. In post-conflict Somalia, the higher education system has dramatically increased with over one hundred universities now open throughout the country with no or little regulations. This time round though, the other two educational forces, the market and oligarchy are playing pivotal roles while that of the government has disappeared. Over the years since the collapse of the state in 1991, the national government's influence decreased ceding so much higher education space, to the five Federal Member States (FMSs). Thus, the situation fits with Clark's dynamic model showing that it is a system capable of reflecting upon ongoing change within the overall socio-political situation. What seems to be developing in the Somali higher education context therefore, is a system in which each force is autonomous with no clear goals shared within the larger structure. As for tertiary education in general, complemented by the rapidly changing world of work, the consensus is 'Having the right qualifications, in the right subjects, from the right institutions' that will benefit all sectors of the economy. It is with that in mind that the disparity between the way in which HE is delivered and the world of work is also examined in this paper. If this important complementarity is not analyzed in the current situation of Somalia, it could pose huge problematic consequences for tertiary education in the country. It is the case that HEIs did not give deserved attention to job market demands as they hardly study that to better serve the needs of employers. collaborative initiatives between the Ministry of Education and Higher Education (MoEHE) and the private sector to support HE is being examined in the final part of this paper.
\end{abstract}

Keywords: Governance Tertiary Education Systems (TES), the state, the market and oligarchy

In his 1983 paper, Clark proposes that the three main forces which shape the nature of a national tertiary education systems are: "the state, the market, and the academic oligarchy". These three are dynamic, frequently changing, and often at odds with each other. There are other equally significant assessment of these forces, such as worldwide political and economic forces, which will

Cultural and Pedagogical Inquiry, Summer 2020, 12(1), pp. 353-359

ISSN 1916-3460 (C) 2020 University of Alberta

http://ejournals.library.ualberta.ca/index.php/cpi/index 
influence any national HES (Marginson, \& Rhoades). In this case, Porter (2008) has proposed five competitive forces:

"(a) the threat of new entrants; (b) the bargaining power of suppliers; (c) the bargaining power of customers; $(d)$ the threat of substitute services; and $(e)$ the degree of rivalry among competing institutions".

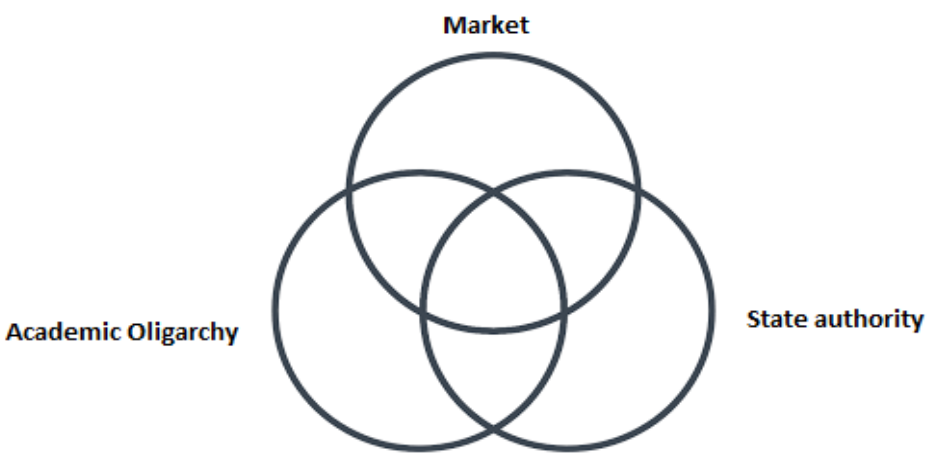

Figure 1. An equal-sided (Venn diagram) Clark's Triangle of Coordination (1983)

In discussing these issues and trends, I am comparatively introducing and analyzing how HES is structured, or inadvertently coordinated, arranged and rearranged since formal Higher Education (HE) had been introduced into the Somali nation-state, with specialized focus on the post-civil war scene. I also briefly examine how and whether this trend is in line with other conventional TESs, and in what manner static frameworks that can capture changes over time from the Somali perspective.

Though a far cry from the evolutionary process the western universities underwent, the history of HE in Somalia experienced uniquely extraordinary metamorphosis and adaptability in its short existence. Before Clark's approach of a disorderly systems of market-like interactions (Maggio, 2012), the power of coordination of top-level policy making for HES in Somalia (and some other African nation-states, for that matter), was primarily under the control of the policy of authority of the day. The role of the academic oligarchy here had been merely limited to middlelevel policy implementation stages with no clout in shaping and coordinating the governance of HES of the country. In the first twenty years, the dynamic system of coordination Clark introduces as the general order for the three dominating forces of educational system, could not have been possible as the state owned and bank-rolled all education. Nonetheless, the role of the University management and academic staff in the only university, which existed at the time, Somali National University (SNU), had been clearly present. That relatively meant that the market and oligarchy subsisted in the shadows of the total governmental control with little or no influence. In summary here therefore, one can argue in that for the twenty or so years the SNU existed under the revolutionary state administration and prior to the civil war, each of the three dominant forms of the system proffered a different mechanism of coordination within the existing academic structure of the nation. All of a sudden, the government, as the sole employer of the graduates from different disciplines and solace of "job guarantee" to everyone, had been almost consigned into minor roles. 


\section{Introducing the "job guarantee" philosophy}

Incidentally, an unintended by-product of the aforementioned system of guaranteeing a job to all graduates (by the government) had been making difficult to estimate the 'quality of the education system. Though guaranteeing a job for every graduate of the only existing university was the policy of the pre-civil war government, it caused a grave information lopsidedness between the consumer, government institutions and the producer, i.e., the HEIs (Beerken, 2015). This approach of authority controlling and safeguarding the quality of education so that it can fill in the societal function became non-functional as that government was removed from power via the civil war of early 1991. That is, and in a reversal of fortunes, when the previous central government ceased functioning, its higher education role expectedly disappeared with the country plunging into an internecine civil strife. With that, the oligarchy, despite existing in an attenuated condition, stepped into the executive authorities' shoes, and the missing market connections also appeared in the system playing a pivotal role.

Ten years or so into the collapse of the previous central government, so named the Somali Democratic Republic, over one hundred universities have been opened throughout Somalia with little or no regulation. Interestingly, after about fifteen years of their existence, these universities went through quite a quick metamorphosis in which some persisted and proved adoptable in the changing circumstances. As could be gleaned from Maggio's (2011) exploration of Clark's triangle forces, all of a sudden, prevailing beliefs and forms of authority shifted. First, the owners of the private HEIs' major goal has always been to increase the intake of students, which remains consequential for their income and revenue. With that, the national government's influence decreased as it ceded so much higher education space to the five Federal Member States (FMSs), the market followed suit. Thus, Clark's dynamic model proved that the current higher education situation represents a system that is capable of reflecting upon, and responding to ongoing change within a system.

As current central government tries to exert its authority, the question that comes into the fray is understanding the types of coordination and the ways in which it interact and reconcile with each other of the three dominant forces in the future. The market demand ought to be accommodated, which consequently makes the triangle of coordination to be a fluid one with that obviously taking some time to become coordinated and stable system. Right now, as Maggio (2012) referencing Clark put it, "the forces of coordination are at least partially exclusive from one another", as are the coordination of academic system features in their interaction and competition. What seems to be developing in the Somali context is a system in which each force is autonomous with no clear goals shared within the larger system, i.e. the central area of the Venn diagram, common to all the forces, does not exist. More often than not, there is a power struggle as each one, particularly state authority, jostles for position in the system. Hopefully, this will eventually bring them to come into the middle ground and assume some balance of their respective roles. Structures are loosely coupled to each other and to ongoing activities. In place of coordination, inspection, and evaluation, a sense of nebulous trust and hazy good faith is developed (Meyer and Rowan, 1977). In short, as almost all HEIs are private, the regulatory role of the state becomes inevitable to avoid confusion in a system of different expectations and conflicting goals. Thus, in Clark's continuum, between the two endpoints of the range lie mixed systems that incorporate elements of both formal linkages and primarily disparate goals including but not limited to federative or coalitional systems (Maggio, 2012).

Cultural and Pedagogical Inquiry, Summer 2020, 12(1), pp. 353-359

ISSN 1916-3460 @ 2020 University of Alberta

http://ejournals.library.ualberta.ca/index.php/cpi/index 
With the case as it has been, what has emerged in post-conflict Somalia is a scheme coordinated primarily by neither the market nor the state, but by an "academic oligarchy". By this term, Clark means the ways in which academics can exert powerful collective voices. Nevertheless, the extent of coordination among academic oligarchy across the country is so far minimal in Somalia. This makes the state intervention inevitable for the system to at least function properly. Thus, the triangle of forces itself stipulates no particular establishing balance for the respective forces in contemporary Somali settings.

It is important to look at the market influence in Somali context of Clark's coordination of HES as there has been heightened attention equated with its role (Williams, 1995; Dill, 2003). There is some semblance of market influence, as the State sponsoring of HE completely disappeared from the system, and the sector opted wholly "for-profit" mode, in which the students and their parents all of a sudden turned out to be sole (customers) driving force.

According to Jongbloed (2003), although the Federal Government (FG), Somaliland and Puntland State have established respective Commissions for Higher Education (CHE), markets for HE usually do not so far exist due to lack of FG policies and regulatory frameworks. In that respect, the degree and type of governmental intervention has been almost non-existent for the first ten years of post-civil war in the areas where relative peace existed such as Puntland and Somaliland. According to Clark's assessment in the market regulatory influence in tertiary education, in some form or other, the supply and demand of the education, research, and engagement activities, and of academic and professional staff, is not evidently clear in Somalia, mainly because the markets role in the business of education is merely unsophisticated one as there is no business model of tertiary education in place so far.

\section{Tertiary education and the rapidly changing world of work}

There is a universal consensus that HE especially makes possible sustainable and inclusive economic and social growth (European Commission referenced by Jongbloed \& Vossensteyn, 2016), thus 'Having the right qualifications, in the right subjects, from the right institutions' will benefit all sectors of the economy (Wolf cited in Jongbloed, 2002). Nowadays, the rapid expansion of practical understanding of subject-dependent service industries and the prerequisite for industrial innovations require employees to be educated and perpetually trained for the required skills in further education sectors. The rapidly-changing world of work is also something that is more tangible and ubiquitously obvious to us as almost half of the jobs in the current labour market will not fit the skills demanded by industry in the near future. That is clear in the industrialized world as automation takes over, and that artificial intelligence will impact on every aspect of our lives. The same goes also for tertiary education (Foundation for Young Australians, 2017). There is huge disparity between the way in which education is delivered and the world of work. Nevertheless, the western hemisphere made inroads on the matter and the gap is moderately narrow in the southern hemisphere as HEIs, Government and employers are in one way or another addressing the matter. In contrast, in Somalia, it's a looming matter of great importance, and if not addressed will have huge consequences for the tertiary education sector of the country. Obviously, people have already started to question the role of almost all of HEIs in with respect to the relevance of the programs and services they deliver.

HE in Puntland, as a microcosm of the overall Somali context, is still in its infancy and faces enormous financial, structural and capacity challenges. Currently, there are more than twelve fullyfunctioning HEIs in Puntland. Nevertheless, as the Foundation for Young Australians (2017) shows, Cultural and Pedagogical Inquiry, Summer 2020, 12(1), pp. 353-359 
automation is predicted to radically affect $70 \%$ of entry-level jobs for young people. This is true for the Puntland setting as there are over five hundred young graduates from those universities in every graduation year, and almost all lack training and transition to work automation skills demanded by the Puntland labor market. The same goes for other FMSs of Somalia.

Even in Australia, for example, it takes a young graduate, on average, more than a year to find full-time work (Foundation for Young Australians, 2017). In sad contrast, due to mismatch of skills acquired by university graduates and job demands required by the employers, private or otherwise, in the FMSs of Somalia, the type of education received renders the young graduate almost unemployable. This reflects how countrywide, HEIs' lack of strategic focus in terms of designing and offering academic programs that are aligned with the priorities of the existing labor market and the development needs of the country.

Somali parents, and government policies in general, encourage ever more secondary leavers to go to university without giving much consideration to the average quality of university education, and whether such education systems is delivering the need to innovate for the young graduates here in the country and beyond including the East African region in the age of globalization.

In order to reverse this trend, universities, governmental institutions, the FG as well as FMSs and private companies ought to address the state of HE including degree programs offered, qualifications of academic staff, nature of employment of the HE alumni, their incomes, their transition to work and the kind of skill sets demanded by the labor market (Jongbloed \& Vossensteyn, 2016).

\section{Recommendations}

To address the above problems, Somali universities should establish career planning offices and placement service centers at university campuses with the objective of enhancing work ethics and applied skills for students, and then make job opportunities information available to them. To achieve this, universities should form an association in order to establish closer working relationship with various job-providing industries and make informed decisions about their study programs. HEIs critically need to reform their offerings and adopt a market- focused approach to better meet the needs of the market and help all sectors gain sustainable economic growth. Consequently, they should phase out programs that are not compatible with the requirements of the local economy and incorporate more Computer Science skills into the syllabus. Similarly, universities need to establish close working relationships with existing high-tech professional bodies. To produce young graduates skilled with entry-level jobs, HEIs should pay special attention in their academic programs to team work, language proficiency, communication, marketing skills and professional ethics.

Somali universities continue to experience extreme shortage of qualified staff. In Puntland, for example, only $9.7 \%$ of the academic staff holds $\mathrm{PhD}$ degrees. Universities and government must continue to intensify their recruitment and retention strategies for qualified academic staff. The MoEHE in conjunction with the universities should look into starting a professional development and upgrading program for HE staff. Institutional capacity building is also necessary to enable HEIs to conduct ongoing research projects. The current situation shows that HEIs country-wide lack strategic focus in terms of designing and offering academic programs that are aligned with the priorities of the labor market and the development needs of the country. According the Heritage Institute for Policy studies (HIPS) report (2013),

Cultural and Pedagogical Inquiry, Summer 2020, 12(1), pp. 353-359

ISSN 1916-3460 @ 2020 University of Alberta

http://ejournals.library.ualberta.ca/index.php/cpi/index 
the concentration of a large number of students in computer-related and business administration courses raises crucial questions about the relevance of courses being offered and their alignment with the human resource needs of the economy and the country's development needs in general.

HEIs do not give deserved attention to the demands of the job market, as they pay little attention to the labor market to better serve the needs of employers. They also lack sufficient facilities and infrastructure necessary for academic excellence. Additionally, the HE policy makers must make sure that current training and education for young HE leavers equips well for the demands of the labor market. In comparison to the HEIs of the region, HE providers, prior to the CHE incipient, operated chiefly as autonomous private entities with no framework to harmonize their programs or oversee the quality of the education they offer, or plan for the general development of $\mathrm{HE}$ as a sector. This decoupled them from the employment market and little or no quality assurance regime.

In so far as Puntland is concerned, as a microcosm of the overall situation in the country, the MoEHE, in recognizing the need for strengthening and tailoring the HE to produce a competent human resource that can support the development needs of the region, completed and established the first HE Act in the State which will govern the HE sector of Puntland. The Ministry has undertaken preliminary labor market survey for HE institutions in order to determine the relationship between university degree programs offered by Puntland HEIs and the skills required by the labor market. In this survey, attention was given to transferrable enterprise skills, such as digital literacy, problem solving and creativity that is needed in the future world of work (Foundation for Young Australians, 2017).

It was targeted qualitative data that identified the gaps that existed between degree programs and labor market requirements. It also examined the capacity of HEIs to close those gaps in an effort to meet the needs of the employment market. Specific attention had been paid in studying graduates who change their career and take jobs outside their fields of study. Follow-up studies are required here to investigate what obstacles and barriers are encountered, in transition to work, by those who did not find a job for longer than a year after graduation.

On the whole, The CHEs of respective states and that of FG and the Ministry of Education should establish labor market study-programmes and conduct bi-annual labor market surveys with yearly updates, analysis and monitoring mechanisms including tracking the number of jobs added to the labor market.

Currently, there are a number of ways in which the private sector is involved in the provision of HE services. The private sector offers some individualized (one-to-one) assistances to certain HEIs, such as sponsoring graduation ceremonies and other events, offering limited internship programs, providing operational support and direct financial assistance. In addition, there have been certain collaborative initiatives between the MoEHE and the private sector to support HE. Therefore, Public Private Partnership already is in place on a small scale.

As for the private sector, there are three important roles, apart from the above individualized assistances, that they could play in the wider Somali HE areas including investment, experience sharing and advocacy. The private sector should invest in educational and research programs based on common priorities in order to address the currently shortage of the aforementioned transferrable 
enterprise skills and to phase out heavy dependency on foreign workers. As for experience sharing, HEIs can learn from the private sector in the following ways: efficient management of resources (e.g., mobilization and utilization); creativity and innovation; Strong work ethics; Employee retention and motivation; Offering demand-led services; accountability; trend analysis; and receiving feedback on skills demanded by the private sector. As for advocacy, the private sector can provide strong advocacy in the following two areas: fundraising and Establishment of regulatory and standardization framework.

\section{References}

Beerkens. M. (2015). Agencification Challenges in Higher Education Quality Assurance. The Transformation of University Institutional and Organizational Boundaries. Sense Publishers, BOX 21858, 3001 AW Rotterdam, The Netherlands.

Clark, B. R. (1983). The higher education system: Academic organization in cross-national perspective. Berkeley, CA: University of California Press.

Dill, D. D. (2003). Allowing the market to rule: The case of the United States. Higher Education Quarterly, Vol. 57, No. 2, pp. 136-157.

Foundation for Young Australians (2017). The new work order: Ensuring young Australians have skills and experience for the jobs of the future, not the past. Retrieved from: http://www.fya.org.au/wp-content/uploads/2015/08/fya-future-of-work-report-final-lr.pdf

HIPS (2013). The State of Higher Education in Somalia. The Heritage Institute for Policy Studies. Mogadishu, Somalia. http://www.heritageinstitute.org/state-of-higher-education/

Jongbloed, B. (2002), Lifelong Learning: Implications for Institutions. Higher Education, Vol. 44, No. 3/4, pp. 413-431.

Jongbloed, B. (2003). Marketization in Higher Education, Clark's Triangle and the Essential Ingredients of Markets. Higher Education Quarterly, Vol. 57, No. 2, pp. 110-135.

Jongbloed, B., \& Vossensteyn, H. (2016). In Conclusion: Doing More with Less New Ways of Providing and Financing Higher Education in the Post-Massification Era. In Access and expansion postmassification: Opportunities and barriers to further growth in higher education participation (pp. 238-253). Routledge. ISBN: 9780415890441.

Maggio, Z. (2012). Exploring Burton Clark's Triangle, A Symposium on Kerr's Life, Work and Legacy. The Steinhardt Institute for Higher Education Policy, New York University.

Meyer J. W., \& Rowan B. (1977). Institutionalized Organizations: Formal Structure as Myth and Ceremony. American Journal of Sociology, Vol. 83, No. 2, pp. 340-363.

Marginson, S., \& Rhoades, G. D. (2002). Beyond national states, markets, and systems of higher education: A glonacal agency heuristic. Higher Education, 43(3), 281-309.

Porter, M. E. (2008). The five competitive forces that shape strategy. Harvard Business Review, 86(1), 78-93.

Williams, G. L. (1995). The 'marketization' of higher education: Reforms and potential reforms in higher education finance. In D. D. Dill and B. Sporn (Eds.), Emerging Patterns of Social Demand and University Reform: Through a Glass Darkly, pp. 170-193. Oxford: Pergamon Press.

Cultural and Pedagogical Inquiry, Summer 2020, 12(1), pp. 353-359

ISSN 1916-3460 @ 2020 University of Alberta

http://ejournals.library.ualberta.ca/index.php/cpi/index 